\title{
Clinical Application of SIRT1 for Diabetes Therapy
}

\section{Yonghua Zhan ${ }^{1}$, Guihai Chen ${ }^{2}$, Yongping Chen ${ }^{3 *}$ and Yongxi Zhao ${ }^{4 *}$}

${ }^{1}$ School of Life Sciences and Technology, Xidian University, Xi'an, Shaanxi 710071, PR China

${ }^{2}$ Department of Neurology, The First Affiliated Hospital of Anhui Medical University, Hefei 230022, Anhui Province, PR China

${ }^{3}$ Department of Biomedical Engineering, Johns Hopkins University, Baltimore, MD. 21205, USA

${ }^{4}$ Key Laboratory of Biomedical Information Engineering of Education Ministry, School of Life Science and Technology, Xi'an Jiaotong University, Xi'an, Shaanxi 710049,

PR China

SIRT1, also known as NAD-dependent deacetylase sirtuin-1, is a protein that in humans is encoded by the SIRT1 gene [1]. Moreover, as a member of the sirtuin family of proteins, homologs of the Sir2 gene in S. cerevisiae, SIRT1 plays an important role in extension of the cell cycle, transcriptional silencing, chromatin homeostasis, DNA damage repair and so on [2]. Recently, many studies demonstrated that SIRT1 is a versatile transcriptional regulator, can deacetylate a variety of transcription factors, such as the FOXO, PGC1-a, p53 and PPAR- $\gamma$ that control metabolism and endocrine signals, and adjust its biological activities [3]. In addition, through regulating the balance of energy metabolism, SIRT1 are widely involved in glucose and lipid metabolism, insulin secretion and other metabolic pathways, so it can maintain a steady state of the body's glucose and lipid metabolism [4].

As we all know, diabetes is a disease because of lack of insulin secretion or insulin resistance [5]. The main reason for the absolute lack of secretion of insulin is that defection of insulin $\beta$-cell for its playing a major important role in the development of type I diabetes [6]. In order to further verify the fact, studies have shown that the majority of genes related to identified types of diabetes have a great relationship with the functional defection of $\beta$-cell [7]. Besides these, it is more important that SIRT1 may be able to restore the function of $\beta$-cell and thereby increase the insulin secretion [8]. So, we can draw a conclusion that SIRT1 may be in contact with diabetes closely.

In order to further clarify its mechanism, many studies verify that SIRT1 with different substrates such as the FOXO, PGC1-a, p53, and PPAR- $\gamma$, play a tissue-specific effects together and activation of the SIRT1 may cause: (1) inhibition of p53 activity, thus inhibiting the pancreatic $\beta$ cell aging and apoptosis, meanwhile extending the life of islet $\beta$ cells; (2) inhibiting the activity of FOXO and enhancing the INS/IGF-1 signaling pathway, thereby improving the insulin sensitivity and reducing $\beta$-cell apoptosis, and at last slowing the aging of $\beta$-cells; (3) inhibiting the transcriptional activity of PPAR- $\gamma$, thus inhibiting the formation of fat cells and fat accumulation; (4) deacetylating the PGC1-a and thus inhibiting the gluconeogenesis to maintain glucose and lipid balance; (5) down-regulating the NF-kB activity, thereby preventing the formation of fatty liver and improving the insulin sensitivity. Thus, researchers have to pay attention to the SIRT1 on the endocrine and metabolic regulation, especially the relationship between SIRT1 and diabetes [9]. More and more evidence suggest that SIRT1 is a significant clinical therapeutic potential target for diabetes. In addition, it is a good measure for the prevention and treatment of diabetes through the activation of SIRT1 [10].

In order to further understand all the action effect of SIRT1 in mammals, especially the role played in the development of diabetes, it is necessary to design and produce gene knock-out transgenic mice, and thus provides deep insight into the SIRT1's biological function and effect [11]. Meanwhile, it is important and necessary to make up for the clinical data and provide direct evidence from clinical patients on the basis of relationship between SIRT1 and diabetes. In addition, in order to better understand the regulating mechanisms and signaling pathways of SIRT1, it is crucial to verify and prove the new substrate effect of SIRT1 protein substrates. Besides these, it is most important to confirm the SIRT1 as a drug targeting through continued development of small molecule agonist biological activity for pharmacology [12].

So, it will provide a good new idea to deeply understand the development process of its regulation of diabetes because of the complexity and contradictions of SIRT1 on the endocrine and metabolic signals regulating it. Furthermore, with the constant awareness of the SIRT1 biological effect, it will contribute to the endocrine and metabolic diseases treatment with the SIRT1 as targeted.

\section{References}

1. Deering TG, Ogihara T, Trace AP, Maier B, Mirmira RG (2009) Methyltransferase Set7/9 maintains transcription and euchromatin structure at islet-enriched genes. Diabetes 58: 185-193.

2. Alcaín FJ, Villalba JM (2009) Sirtuin activators. Expert Opin Ther Pat 19: 403414

3. Pacholec M, Bleasdale JE, Chrunyk B, Cunningham D, Flynn D, et al. (2010) SRT1720, SRT2183, SRT1460, and resveratrol are not direct activators of SIRT1. J Biol Chem 285: 8340-8351.

4. Vaziri H, Dessain SK, Ng Eaton E, Imai SI, Frye RA, et al. (2001) hSIR2(SIRT1) functions as an NAD-dependent p53 deacetylase. Cell 107: 149-159.

5. Motta MC, Divecha N, Lemieux M, Kamel C, Chen D, et al. (2004) Mammalian SIRT1 represses forkhead transcription factors. Cell 116: 551-563.

6. Deloukas P, Earthrowl ME, Grafham DV, Rubenfield M, French L, et al. (2004) The DNA sequence and comparative analysis of human chromosome 10 Nature 429: 375-381.

7. Picard F, Kurtev M, Chung N, Topark-Ngarm A, Senawong T, et al. (2004) Sirt1 promotes fat mobilization in white adipocytes by repressing PPAR-gamma. Nature 429: 771-776.

8. Cohen HY, Miller C, Bitterman KJ, Wall NR, Hekking B, et al.

$(2004)$

*Corresponding authors: Yongping Chen, Department of Biomedical Engineering, Johns Hopkins University, Baltimore, MD. 21205, USA, E-mail: yongpc@jhu.edu

Yongxi Zhao, Key Laboratory of Biomedical Information Engineering of Education Ministry, School of Life Science and Technology, Xi'an Jiaotong University, Xi'an, Shaanxi 710049, PR China, E-mail: yxzhao@mail.xjtu.edu.cn

Received July 24, 2012; Accepted July 26, 2012; Published July 30, 2012

Citation: Zhan Y, Chen G, Chen Y, Zhao Y (2012) Clinical Application of SIRT1 for Diabetes Therapy. J Pharmacogenom Pharmacoproteomics 3: e121. doi:10.4172/2153-0645.1000e121

Copyright: (c) 2012 Zhan Y, et al. This is an open-access article distributed under the terms of the Creative Commons Attribution License, which permits unrestricted use, distribution, and reproduction in any medium, provided the original author and source are credited. 
Citation: Zhan Y, Chen G, Chen Y, Zhao Y (2012) Clinical Application of SIRT1 for Diabetes Therapy. J Pharmacogenom Pharmacoproteomics 3: e121. doi:10.4172/2153-0645.1000e121

Page 2 of 2

Calorie restriction promotes mammalian cell survival by inducing the SIRT1 deacetylase. Science 305: 390-392.

9. Strausberg RL, Feingold EA, Grouse LH, Derge JG, Klausner RD, et al. (2002) Generation and initial analysis of more than 15,000 full-length human and mouse cDNA sequences. Proc Natl Acad Sci USA 99: 16899-16903.

10. Saini A, Al-Shanti N, Sharples AP, Stewart CE (2011) Sirtuin 1 regulates skeletal myoblast survival and enhances differentiation in the presence of resveratrol. Exp Physiol 97: 400-418.
11. Peng L, Ling H, Yuan Z, Fang B, Bloom G, et al. (2012) SIRT1 Negatively Regulates the Activities, Functions, and Protein Levels of hMOF and TIP60. Mol Cell Biol 32: 2823-2836.

12. Velasquez DA, Martinez G, Romero A, Vazquez MJ, Boit KD, et al. (2011) The Central Sirtuin 1/p53 Pathway Is Essential for the Orexigenic Action of Ghrelin. Diabetes 60: 1177-1185. 